\title{
Optimal design of feeding system in steel casting by constrained optimization algorithms based on InteCAST
}

\author{
Chang-chun Dong, Xu Shen, *Jian-xin Zhou, Tong Wang, and Ya-jun Yin \\ State Key Laboratory of Materials Processing and Die \& Mould Technology, Huazhong University of Science and Technology, Wuhan 430074, \\ Hubei, China
}

\begin{abstract}
The traditional foundry industry has developed rapidly in recently years due to advancements in computer technology. Modifying and designing the feeding system has become more convenient with the help of the casting software, InteCAST. A common method of designing a feeding system is to first design the initial systems, run simulations with casting software, analyze the feedback, and then redesign. In this work, genetic, fruit fly, and interior point optimizer (IPOPT) algorithms were introduced to guide the optimal riser design for the feeding system. The results calculated by the three optimal algorithms indicate that the riser volume has a weak relationship with the modulus constraint; while it has a close relationship with the volume constraint. Based on the convergence rate, the fruit fly algorithm was obviously faster than the genetic algorithm. The optimized riser was also applied during casting, and was simulated using InteCAST. The numerical simulation results reveal that with the same riser volume, the riser optimized by the genetic and fruit fly algorithms has a similar improvement on casting shrinkage. The IPOPT algorithm has the advantage of causing the smallest shrinkage porosities, compared to those of the genetic and fruit fly algorithms, which were almost the same.
\end{abstract}

Key words: casting process design; optimal solution; InteCAST

CLC numbers: TG269 Document code: A Article ID: 1672-6421(2016)06-375-08

$\mathrm{C}$ asting is a manufacturing process that has existed for over $\theta \quad \&$ ars ${ }^{[1]}$. In times $b$ fore the , the casting process developed through a "trial-and-error" method, which is time-consuming, expensive, and results in sub-optimal final products. In 1962, Fursund ${ }^{[2]}$ was the first to use computers to simulate casting temperature fields. Universities and research institutions have since pursued research and development to numerically simulate casting technology ${ }^{[3-5]}$. During the past three decades, casting simulations have been widely used in the foundry industry. Many casting programs facilitate the casting design process.

Nonetheless, significant progress must be made to improve this simulation software. Casting software can predict defects in the casting, but it cannot determine whether or not the process is optimal. Complex simulation calculations must be performed on computers to discover

\section{*Jian-xin Zhou}

Male, born in 1975, Ph.D. and Professor. His research is mainly on research and development of production management and numerical simulations of material processes like casting, welding, and composite.

E-mail: zhoujianxin@ hust.edu.cn

Received: 2016-01-05; Accepted: 2016-09-20 better results and lower costs by producing lower production cycles and lower riser volumes. Since the feeding system and gating system are abandoned after the casting process, and both of them especially the former one have some weight, that makes the technological yield of casting not too high, about $50 \%-80 \%$. It is beneficial to develop an optimal method that optimizes the feeding system while improving casting quality.

In recent years, many researchers have explored optimal solutions for the casting process. Lewis et al. ${ }^{[6]}$ reported successful use of optimization methods in optimizing the riser design. Albu and Zubov ${ }^{[7]}$ considered the optimal control problem for the solidification process in metal casting. Tavakoli and Davami ${ }^{[8]}$ used the evolutionary topology optimization to improve the feeding system design. Zhou and Gong et al. ${ }^{[9,10]}$ used the design of experiments (DOE) to investigate the best process parameters for the casting process. By implementing DOE, further work must be done in orthogonal design calch ations. These metho have the id sada ntag of high computational costs, but they can solve problems associated with casting.

In the present study, three optimal algorithms were proposed to optimize the riser design process. A casting 
simulation of an adjustment ring based on InteCAST was presented. The optimal methods can reduce computational time and achieve a high-quality casting product.

\section{Casting process simulation and optimization with InteCAST}

\subsection{Mathematical models}

In computational fluid dynamics (CFD), the computer simulations of a molten metal flow field and a temperature field are based on a continuity equation, a momentum conservation equation, an energy conservation equation, and a volume function equation ${ }^{[11,12]}$. Casting simulation includes two stages: filling the mold with molten metal, and then solidification. In the mold-filling stage, a continuity equation ensures that the in-flow volume equals the out-flow volume, which can be expressed as:

$$
\frac{\partial \rho}{\partial t}+\nabla \cdot(\rho \mathbf{u})=0
$$

where $\rho$ is the molten metal density, $t$ is the time, and $\mathbf{u}$ is the vector field of the molten metal flow velocity.

In the fluid area, the physical meaning of the momentum conservation equation is in unit time, the sum of the momentum flow into the volume plus force acting on the volume is equal to the increase of momentm in the volm e. The momentm conservation equation for the incompressible flow can be described as:

$$
\rho \frac{\partial \mathbf{u}}{\partial t}+\rho \mathbf{u} \cdot \nabla \mathbf{u}=\mu \nabla^{2} \mathbf{u}-\nabla p+\rho \mathbf{g}
$$

where $\mu$ is the viscosity of the molten metal, $p$ is the pressure, representing the normal force per unit area, and $\mathbf{g}$ is the gravitational acceleration.

The total energy in a volume is constant. The energy conservation equation of the molten metal can be described as:

$$
\rho c_{p} \frac{D T}{D t}=\nabla \cdot(k \nabla T)+Q
$$

where $c_{\mathrm{p}}$ is the specific heat of the molten metal, $T$ is the temperature, $k$ is the thermal conductivity of the molten metal, and $Q$ is the internal heat.

The VOF method is $\mathbf{s}$ ed to trace the flow front evolt ion. The function of the volume can be described as:

$$
\frac{\partial F}{\partial t}+\mathbf{u} \cdot \nabla F=0
$$

where $F$ is the volume function.

\subsection{Quantitative casting defect prediction}

The mold filling stage is a process of high-temperature molten metal entering and filling the mold through the gating system, which determines the final quality of the product, as it is heavily affected by casting defects such as cold shuts, misruns, gas holes, shrinkage, and dispersed shrinkage. The mold-filling process can be analyzed by casting simulation software to predict casting defects for a variety of alloy types and casting methods. An optimal casting process can then be designed to improve product quality ${ }^{[13,14]}$.

In casting simulation software, quantitative prediction results are already realistic. For instance, in steel casting, shrinkage is the most common defect. They can be visually observed from the post-processor of InteCAST. Figure 1 shows the statistical results of shrinkage cavities and porosities of a casting, which was obtained by simulation analysis. Since shrinkage reduces casting quality, the optimal method must be used to avoid shrinkage, helping enterprises reduce production costs and obtain higher quality products.

\subsection{Casting process optimia tion}

\subsubsection{Optimal strategy}

One of the most used strategies for casting process optimization is the feeding system optimization, as shown in Fig. 2.

Because the minimum volume is the target, the volume of the

\begin{tabular}{|l|l|l|}
\hline No. & Type & Vol $\left(\mathrm{cm}^{3}\right)$ \\
\hline 1 & Cavity & 25.25 \\
\hline 2 & Porosity & 6.25 \\
\hline 3 & Porosity & 1.50 \\
\hline 4 & Porosity & 1.38 \\
\hline 5 & Porosity & 59.13 \\
\hline$\ldots$ & $\ldots$ & \\
\hline
\end{tabular}
objective function:

$\operatorname{Min} f(x)=\operatorname{Vr}(D, H, d, h)$

On the other hand, the design should obey the following rules: a feeding channel must exist between the feeder and the feeding part in the casting; the neck of the feeder should maintain a certain height, generally greater than $1.5 \mathrm{~cm}$; to ensure the shrinkage produced in the feeder, the feeder should maintain a certain height; the solidification time of the feeder should exceed the solidification time of the

Fig. 1: Quantitative shrinkage prediction 


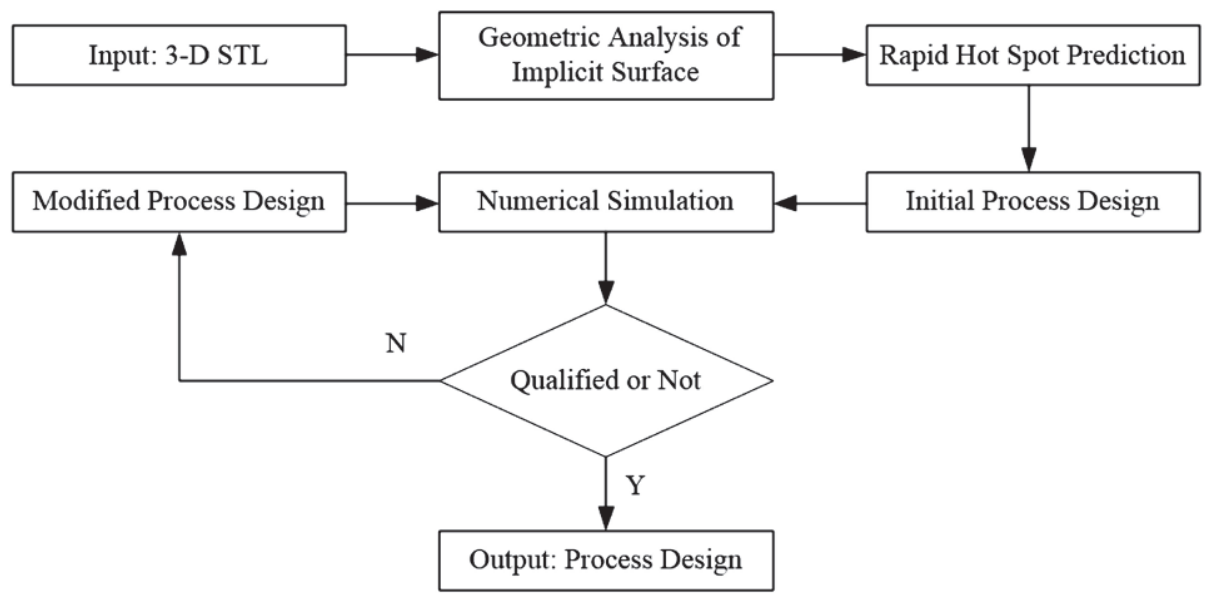

Fig. 2: Feeding system optimization strategy

feeding part in the casting; and the feeder should maintain enough liquid metal to feed the casting.

The expression of a side riser is presented as an example. The objective function is as follows:

$$
V=\pi\left(H D^{2}+h d^{2}\right) / 4
$$

The constrained condition is as follows:

$$
\left\{\begin{array}{l}
D \in\left[0.5 d_{r}, 2 d_{r}\right] \\
H \in[D, 1.5 D] \\
d \in[0.75 D, D-1] \\
h \in[15, d], \text { if } d \geq 30 \mathrm{~mm}, h \in[15,30]
\end{array}\right.
$$

where $d_{\mathrm{r}}$ is equivalent diameter of riser calculated by cubic equation method ${ }^{[15]}$. The other parameters refer to identification in Fig. 3.
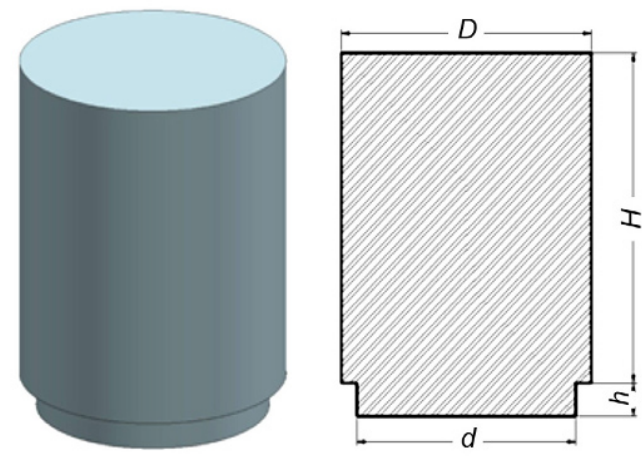

Fig. 3: Typical open riser in steel casting

\subsubsection{Optimal algorithm}

\section{(a) Genetic algorithm}

The basic theory of genetic algorithm ${ }^{[16]}$ comes from Darwin's theory of evolution and Mendelian genetic theory. Implementing a genetic algorithm can be divided into three steps: 1) choose the individuals with high adaptability, and let them survive and produce offspring; 2) reorganize and crossover to produce new individuals; 3) mutate excellent genes or defective ones. To find the optimal solution, encoding is necessary first, and then the code must be transferred to a language that a computer can identify. After evaluating individual fitness, the superior one was selected and the inferior ones were eliminated. Finally, the genetic operation was continued to find the optimal solution with the iteration procedure. Figure 4 shows a flow chart of the genetic algorithm.

(b) Fruit fly algorithm

The fruit fly algorithm ${ }^{[17,18]}$ can simultaneously optimize riser diameters, riser heights, riser neck diameters, and riser neck heights. The riser optimization process can be concluded as follows:

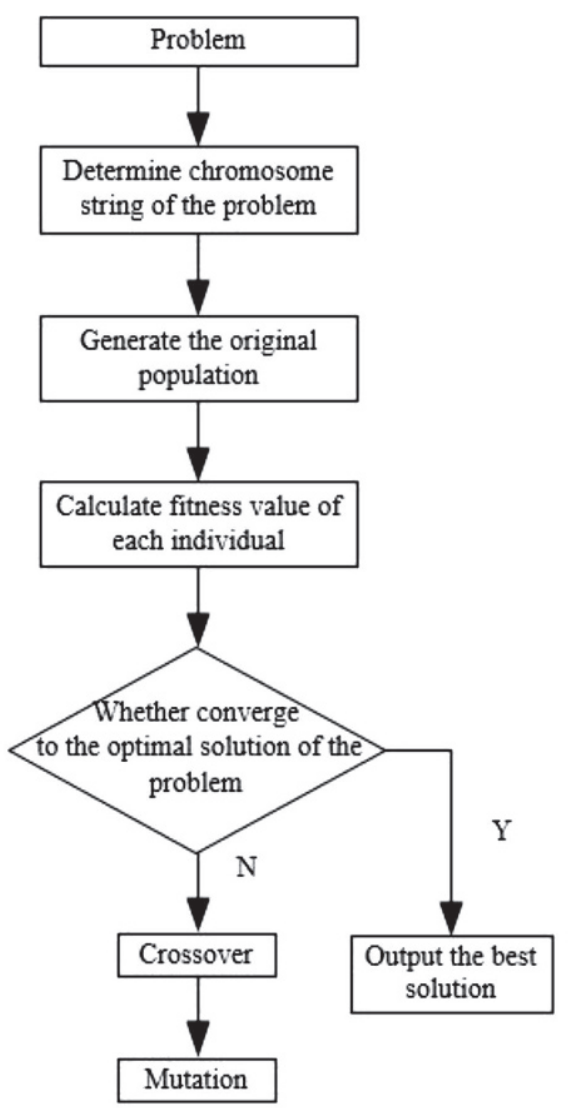

Fig. 4: Flow chart of genetic algorithm 
1) Initiate the location of fly groups $\left(X_{1,0}, Y_{1,0}\right)$, $\left(X_{2,0}, Y_{2,0}\right),\left(X_{3,0}, Y_{3,0}\right),\left(X_{4,0}, Y_{4,0}\right)$ randomly. The subscript 1 represents riser diameters, 2 represents riser heights, 3 represents riser neck diameters, and 4 represents riser neck heights.

2) Let an individual fruit fly search a random direction and distance for food. $X_{1, i}=X_{1,0}+$ random value, $Y_{1, i}=Y_{1,0}+$ random value; $X_{2, i}=X_{2,0}+$ random value, $Y_{2, i}=Y_{2,0}+$ random value; $X_{3, i}=X_{3,0}+$ random value, $Y_{3, i}=Y_{3,0}+$ random value; $X_{4, i}=X_{4,0}+$ random value, $Y_{4, i}=Y_{4,0}+$ random value. The subscript $i$ represents the population size.

3) Calculate the distance to the origin $D_{1, i}, D_{2, i}, D_{3, i}$, $D_{4, i}$, then calculate the smell concentration judgement value $S_{1, i}=1 / D_{1, i}, S_{2, i}=1 / D_{2, i}, S_{3, \mathrm{i}}=1 / D_{3, i}, S_{4, i}=1 / D_{4, i}$.

4) Determine whether the smell concentration judgement value satisfies the given constraints of the range; if it is satisfied, proceed to the next step; if not, repeat steps (2)-(3). Range constraints are defined as $0.5 d_{\mathrm{r}} \leqslant S_{1, i} \leqslant 2 d_{\mathrm{r}} ; S_{1, i} \leqslant S_{2, i} \leqslant 1.5 S_{1, i} ; 0.75 S_{1, i} \leqslant \mathrm{~S}_{3, i} \leqslant$ $\mathrm{S}_{1, i}-1$. The height range of the riser neck are divided into two parts: when $S_{3, i}<30,15 \leqslant S_{4, i} \leqslant S_{3, i}$; when $S_{3, i}$ $\geqslant 30,15 \leqslant S_{4, i} \leqslant 30$.

5) Substitute the smell concentration judgement value into the smell concentration judgement function to obtain the smell concentration of the fruit flies' individuals position $f\left(S_{1, i}, S_{2, i}, S_{3, i}, S_{4, i}\right)$.

6) Determine whether or not the riser diameters, riser heights, riser neck diameters, and riser neck heights meet the constraint conditions.

7) Locate the fruit flies with the lowest smell concentration in the fruit fly group $\operatorname{Min}\left(V_{i}\right)$; that is, the minimum value of the riser volume.

8) Keep the best taste concentration $V_{\text {index, best }}=\operatorname{Min}\left(V_{i}\right)$ and coordinate $\left(X_{n, \text { best }}, Y_{n, \text { best }}\right)=\left(X_{n, \text { index }}, Y_{n, \text { index }}\right)(n=1,2,3,4)$.

9) Go to the iterative optimization, repeat steps (2)-(7), and judge whether the smell concentration is less than that of the previous iteration; if so, implement step (8). Figure 5 shows a flow chart of the fruit fly algorithm.

\section{(c) IPOPT Algorithm}

The IPOPT ${ }^{[19]}$ algorithm is generally used to calculate largescale non-linear optimal problems. Its approach is to calculate a series of barrier problems. The detailed steps are:

1) Take a moderate value of the barrier parameter; the user provides a starting point to solve the relevant barrier problem with loose precision;

2) Reduce the value of the barrier parameter, solve the next problem with a tighter precision, use the approximate solution beforehand as a new starting point, and then continue to solve the barrier problems;

3) Repeat procedure 2) to obtain a solution that satisfies the precision requirements. Figure 6 shows a flow chart of the IPOPT algorithm.

\section{Exemplifications}

\subsection{Process design for adjustment ring}

\subsubsection{Basic parameters for the adjustment ring}

This section gives an example of an adjustment ring. Figure

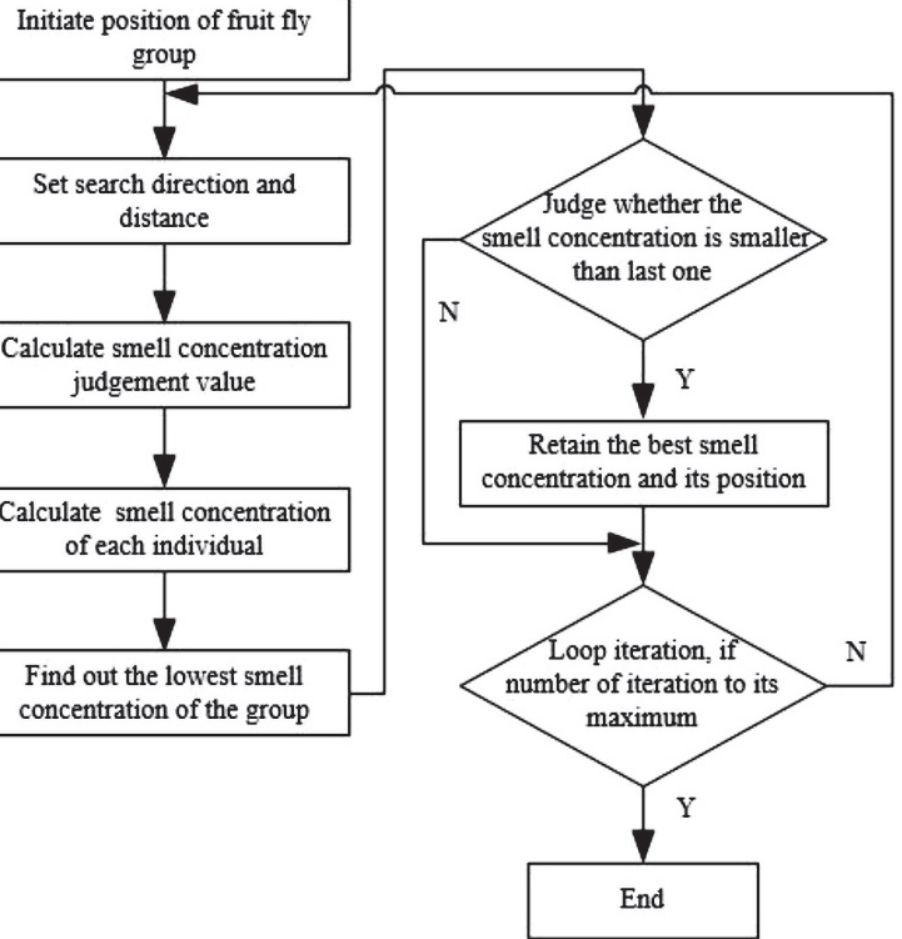

Fig. 5: Flow chart of fruit fly algorithm

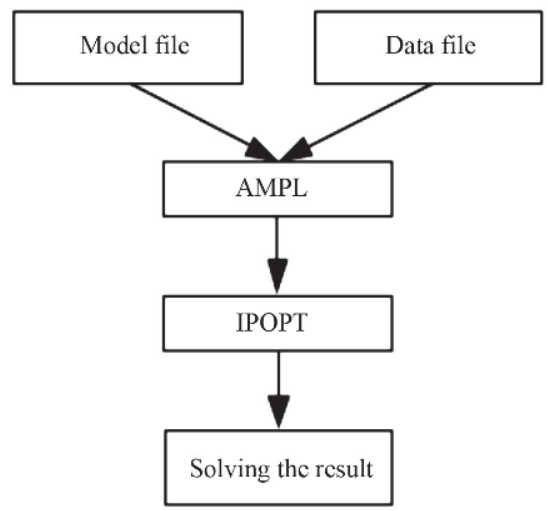

Fig. 6: Flow chart of IPOPT algorithm

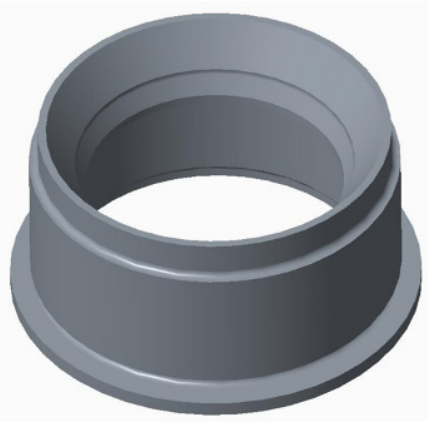

Fig. 7: Geometry of adjustment ring

7 shows its geometry. The material of the adjustment ring is ZG45; Table 1 shows the properties of ZG45. The following describes how to design the simulation analysis and evaluation, and process optimization.

\subsubsection{Optimal steps for the adjustment ring}

Figure 8 shows the basic optimal steps for designing the 
Table 1: Properties of ZG45

\begin{tabular}{cc} 
Properties & Value \\
\hline Density $\left(\mathrm{kg} \cdot \mathrm{m}^{-3}\right)$ & 7600 \\
Specific heat capacity $\left(\mathrm{J} \cdot \mathrm{Kg}^{-1} \cdot{ }^{\circ} \mathrm{C}^{-1}\right)$ & 602.11 \\
Thermal conductivity $\left(\mathrm{W} \cdot \mathrm{m}^{-1} \cdot{ }^{\circ} \mathrm{C}^{-1}\right)$ & 24.02 \\
Viscosity $(\mathrm{Pa} \cdot \mathrm{s})$ & 0.0456 \\
Latent heat $\left(\mathrm{J} \cdot \mathrm{Kg}^{-1}\right)$ & $2.51 \times 10^{5}$ \\
Liquidus temperature $\left({ }^{\circ} \mathrm{C}\right)$ & 1495.68 \\
Solidus temperature $\left({ }^{\circ} \mathrm{C}\right)$ & 1408.04 \\
Critical solid fraction & 0.65 \\
Phase change shrinkage & 0.04
\end{tabular}

castings: (a) build a three-dimensional geometric model in terms of actual casting information; (b) proceed with the initial design for a gating system and riser pad in accordance with the principle of process design; (c) partition the casting based on the casting characteristics; dividing the adjustment ring into four equal regions is considered to be reasonable; (d) obtain the dimensions of the riser at one region through three optimal algorithms; (e) since the adjustment ring is axisymmetric, the calculated riser can be applied to the rest of the risers. In this work, the optimal solution is for the riser only; the gating system follows the initial design.

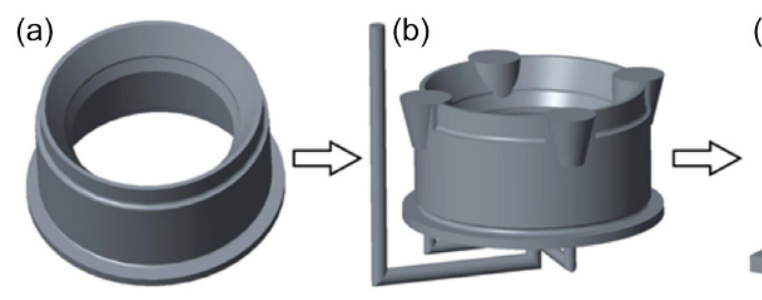

(c) (e)

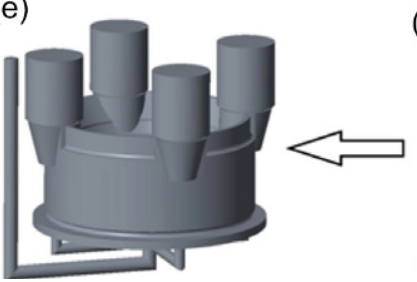

(d)
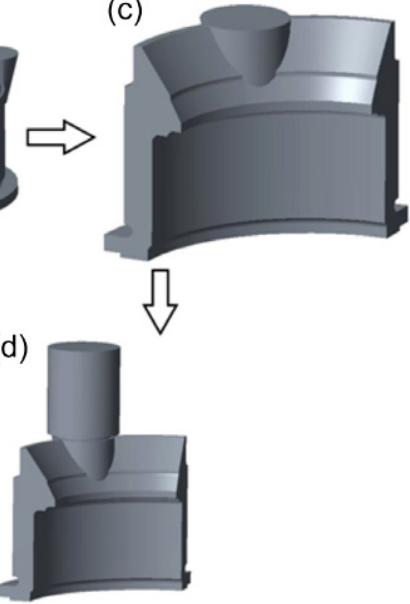

Fig. 8: Basic optimal steps for castings

\subsection{Optimal solutions}

The feeding volume is $82,339,112 \mathrm{~mm}^{3}$, the area is $2,023,110$ $\mathrm{mm}^{2}$, and the modulus is $40.70 \mathrm{~mm}$. The population is 100 , the gene number is 24 , the crossing rate is 0.8 , the aberration rate is 0.1 , the modulus constraint is 1.1 , and the volume constraint is 0.56 . The metal volume shrinkage is $5 \%$, and the riser feeding efficiency is $14 \%$. Table 2 shows the optimal results.

When the generations and modulus constraint are fixed, as the volume constraint increases, the riser volume increases. When the generations and volume constraints are fixed, the riser volume is almost invariant as the modulus constraint increases.

The population is 100 , the metal volume shrinkage is $5 \%$, and the riser feeding efficiency is $14 \%$. Table 3 shows the optimal results. Table 3 indicates that when the volume constraint is fixed, the riser volume changes very little as the generations or modulus constraint change. However, the riser volume increases as the volume constraint increases.

The metal volume shrinkage is $5 \%$ and the riser feeding efficiency is $14 \%$. Table 4 shows the optimal results. From the table, when the volume constraint is fixed, the riser volume remains constant with the increase of generations or the modulus constraint. The riser volume increases as the volume constraint increases.

\subsection{Comparison and analysis}

All three algorithms adapt to 10,000 iterations. The modulus constraint is 1.1 and the volume constraint is 0.56 . The metal volume shrinkage is $5 \%$ and the efficiency of the riser feeding is $14 \%$. The critical shrinkage cavity ratio and critical shrinkage porosity ratio are 0.6 and 0.01 , respectively.

\subsubsection{Solidification of the steel casting}

Figure 9 shows the optimization results. In Fig. 9, the brown represents molten metal in the solidification process, black represents a shrinkage cavity, and purple represents shrinkage porosities. The simulation results show that after complete molten metal solidification, there were no shrinkage cavities in the casting adjustment ring, only some shrinkage porosities left in the casting. The total shrinkage porosity volumes for the genetic algorithm, fruit fly algorithm, and IPOPT algorithm were $5.0534 \times 10^{5} \mathrm{~mm}^{3}, 6.3949 \times 10^{5} \mathrm{~mm}^{3}$, and $2.0070 \times 10^{5}$ $\mathrm{mm}^{3}$, respectively. There was a relatively significant amount of shrinkage porosity residue in the adjustment ring for the genetic algorithm and fruit fly algorithm, while calculations by IPOPT algorithm showed relatively few defects in the casting. Thus, in this casting, the sort order of algorithm optimization for red ing the shrink $g$ volm e is IPOPT algr ithm $>g$ netic algorithm $>$ fruit fly algorithm.

Figure 9 also shows that the process required $4554.72 \mathrm{~s}$, $4382.21 \mathrm{~s}$, and $3702.23 \mathrm{~s}$ to complete solidification for the genetic algorithm, fruit fly algorithm, and IPOPT algorithm, respectively. The IPOPT algorithm obviously outperformed the other 2 algorithms in speed. 
Table 2: Results of genetic algorithm optimia tion

$\begin{array}{ccccccccc}\text { Generations } & \begin{array}{c}\text { Modulus } \\ \text { constraint }\end{array} & \begin{array}{c}\text { Volume } \\ \text { constraint }\end{array} & \begin{array}{c}\text { Riser diameter } \\ \boldsymbol{D}(\mathbf{m m})\end{array} & \begin{array}{c}\text { Riser height } \\ \boldsymbol{h}(\mathbf{m m})\end{array} & \begin{array}{c}\text { Riser neck } \\ \text { diameter } \\ \mathbf{d}(\mathbf{m m})\end{array} & \begin{array}{c}\text { Riser Neck } \\ \text { height } \\ \boldsymbol{h}(\mathbf{m m})\end{array} & \begin{array}{c}\text { Riser volume } \\ (\mathbf{m m})^{3}\end{array} \\ 1000 & 1.1 & 0.56 & 350.368 & 464.376 & 309.508 & 17.8571 & 4.61157 \times 10^{7} \\ 5000 & 1.1 & 0.56 & 350.368 & 456.034 & 304.01 & 29.5238 & 4.61109 \times 10^{7} \\ 10000 & 1.1 & 0.56 & 374.531 & 407.228 & 300.013 & 17.619 & 4.611 \times 10^{7} \\ 10000 & 1.2 & 0.56 & 374.531 & 407.228 & 317.657 & 15.7143 & 4.61099 \times 10^{7} \\ 10000 & 1.3 & 0.56 & 362.449 & 431.487 & 307.397 & 21.4286 & 4.611 \times 10^{7} \\ 10000 & 1.1 & 1.06 & 428.898 & 582.076 & 412.723 & 23.8095 & 8.7285 \times 10^{7} \\ 10000 & 1.1 & 1.56 & 477.225 & 704.475 & 387.965 & 21.1905 & 1.28514 \times 10^{8}\end{array}$

Table 3: Results of fruit fly algorithm optimization

\begin{tabular}{|c|c|c|c|c|c|c|c|}
\hline Generations & $\begin{array}{l}\text { Modulus } \\
\text { constraint }\end{array}$ & $\begin{array}{l}\text { Volume } \\
\text { constraint }\end{array}$ & $\begin{array}{c}\text { Riser diameter } \\
D(\mathrm{~mm})\end{array}$ & $\begin{array}{l}\text { Riser height } \\
\qquad h(\mathrm{~mm})\end{array}$ & $\begin{array}{c}\text { Riser neck } \\
\text { diameter } \\
\text { d (mm) }\end{array}$ & $\begin{array}{c}\text { Riser neck } \\
\text { height } \\
h(\mathrm{~mm})\end{array}$ & $\begin{array}{l}\text { Riser volume } \\
\left(\mathrm{mm}^{3}\right)\end{array}$ \\
\hline 1000 & 1.1 & 0.56 & 370.2112 & 406.1573 & 328.3046 & 28.2550 & $4.6112 \times 10^{7}$ \\
\hline 5000 & 1.1 & 0.56 & 371.6091 & 407.6361 & 293.4382 & 28.0885 & $4.6111 \times 10^{7}$ \\
\hline 10000 & 1.1 & 0.56 & 378.8552 & 393.5379 & 309.4627 & 23.2243 & $4.6110 \times 10^{7}$ \\
\hline 10000 & 1.2 & 0.56 & 375.5438 & 395.4967 & 322.5934 & 28.1633 & $4.6110 \times 10^{7}$ \\
\hline 10000 & 1.3 & 0.56 & 374.3853 & 402.1445 & 332.7875 & 21.1537 & $4.6110 \times 10^{7}$ \\
\hline 10000 & 1.1 & 1.06 & 434.2150 & 570.5359 & 365.9770 & 26.5669 & $8.7280 \times 10^{7}$ \\
\hline 10000 & 1.1 & 1.56 & 496.2514 & 638.1701 & 476.6339 & 28.1208 & $1.2845 \times 10^{8}$ \\
\hline
\end{tabular}

Table 4: Results of IPOPT algorithm optimia tion

\begin{tabular}{|c|c|c|c|c|c|c|}
\hline $\begin{array}{l}\text { Modulus } \\
\text { constraint }\end{array}$ & $\begin{array}{l}\text { Volume } \\
\text { constraint }\end{array}$ & $\begin{array}{c}\text { Riser diameter } \\
D(\mathrm{~mm})\end{array}$ & $\begin{array}{l}\text { Riser height } \\
\qquad h(\mathrm{~mm})\end{array}$ & $\begin{array}{l}\text { Riser neck } \\
\text { diameter d } \\
\text { (mm) }\end{array}$ & $\begin{array}{c}\text { Riser neck } \\
\text { height } h \\
(\mathrm{~mm})\end{array}$ & $\begin{array}{l}\text { Riser volume } \\
\left(\mathrm{mm}^{3}\right)\end{array}$ \\
\hline 1.1 & 0.56 & 337.054 & 501.128 & 254.384 & 27.4771 & $4.61099 \times 10^{7}$ \\
\hline 1.2 & 0.56 & 337.073 & 501.071 & 254.443 & 27.4673 & $4.61099 \times 10^{7}$ \\
\hline 1.3 & 0.56 & 337.113 & 500.969 & 254.51 & 27.4232 & $4.61099 \times 10^{7}$ \\
\hline 1.1 & 1.06 & 417.207 & 622.596 & 313.92 & 27.98 & $8.72795 \times 10^{7}$ \\
\hline 1.1 & 1.56 & 474.777 & 709.582 & 356.813 & 28.2527 & $1.28449 \times 10^{8}$ \\
\hline
\end{tabular}

\subsubsection{Shrinkage distribution in the riser}

Figure 10 shows the shrinkage cavity and porosity distribution in the riser. The volumes of the shrinkage cavity for the genetic algorithm, fruit fly algorithm, and IPOPT algorithm are $6.9 \times 10^{6}$ $\mathrm{mm}^{3}, 6.95 \times 10^{6} \mathrm{~mm}^{3}$, and $6.75 \times 10^{6} \mathrm{~mm}^{3}$, respectively. The shrinkage porosity volume is $7.0759 \times 10^{5} \mathrm{~mm}^{3}, 7.2090 \times 10^{5}$ $\mathrm{mm}^{3}$, and $6.8148 \times 10^{5} \mathrm{~mm}^{3}$, respectively. For the genetic algorithm and fruit fly algorithm, part of the shrinkage porosities were residual in the casting adjustment ring. The vertical length of shrinkage porosity left in the adjustment ring for the two algorithms were $60.25 \mathrm{~mm}$ and $64.55 \mathrm{~mm}$, respectively. The IPOPT algorithm obtained better results; the shrinkage porosity is far away from the adjustment ring, and their distance is 61.27 $\mathrm{mm}$. The riser optimal effect for the three optimal algorithms is as follows: IPOPT algorithm is the best, followed by the genetic algorithm, and then the fruit fly algorithm.

\section{Conclusions}

In this study, three optimal solutions were applied to the casting process to improve the riser system design: genetic algorithm, fruit fly algorithm, and IPOPT algorithm. By studying the casting process of an adjustment ring, the following conclusions can be drawn:

(1) The riser volume remained constant as the modulus constraint increased, and increased as the volume constraint increased. The riser size was sensitive with the volume constraint.

(2) Calculations were carried out for the three algorithms in riser optimization. All three optimal algorithms adapted to 10000 iterations, and the modulus constraint was 1.1 and the volume constraint was 0.56 . The numerical calculations showed that there were no shrinkage cavities in casting, and only some shrinkage porosities remained.

(3) The casting process optimized by IPOPT algorithm 


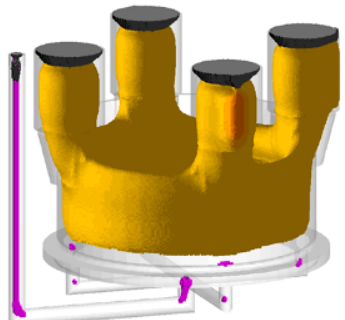

$\mathrm{t}=901.19 \mathrm{~s}$

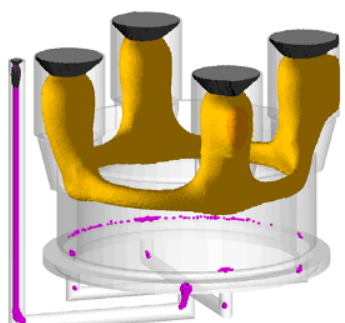

$t=1601.43 \mathrm{~s}$

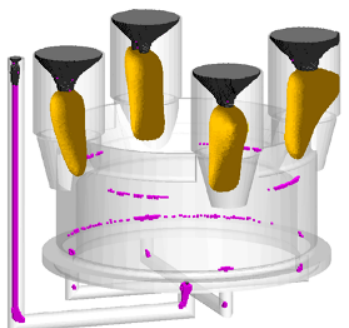

$\mathrm{t}=3001.95 \mathrm{~s}$

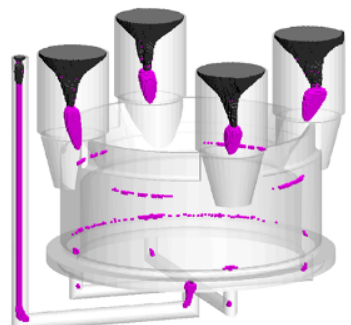

$\mathrm{t}=4554.74 \mathrm{~s}$

(a) Genetic algorithm

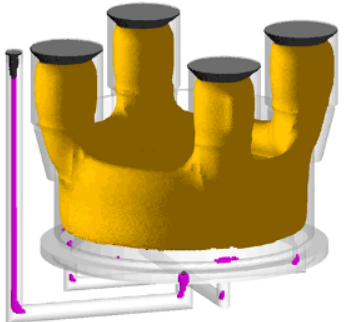

$\mathrm{t}=901.19 \mathrm{~s}$

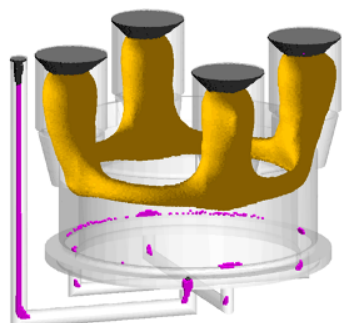

$\mathrm{t}=1601.43 \mathrm{~s}$

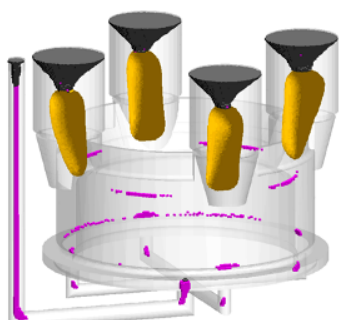

$\mathrm{t}=3001.95 \mathrm{~s}$

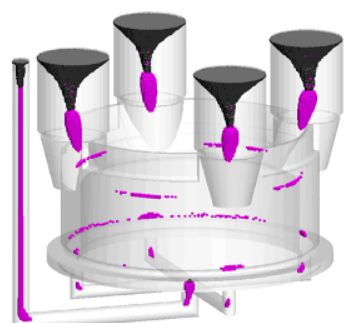

$\mathrm{t}=4382.21 \mathrm{~s}$

(b) Fruit fly algorithm

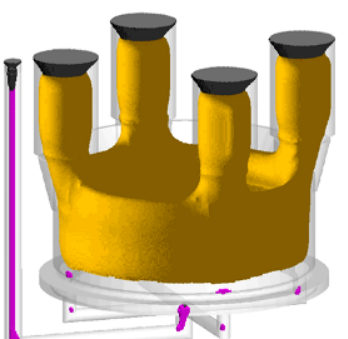

$\mathrm{t}=901.19 \mathrm{~s}$

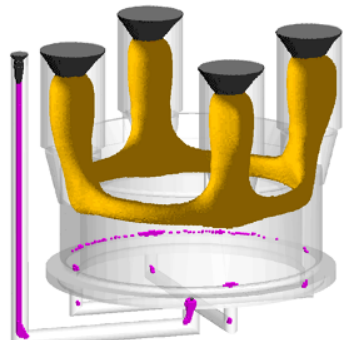

$\mathrm{t}=1601.43 \mathrm{~s}$

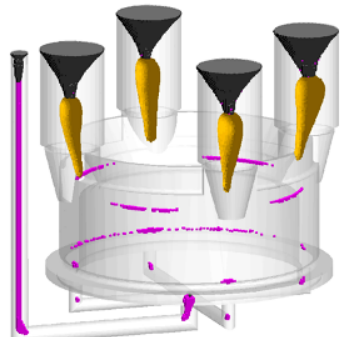

$\mathrm{t}=3001.95 \mathrm{~s}$

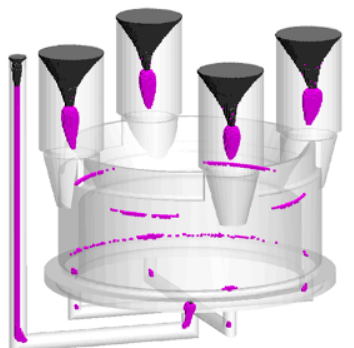

$\mathrm{t}=3702.23 \mathrm{~s}$

(c) IPOPT algorithm

Fig. 9: Simulation results for different optimization algorithms: (a) Genetic algorithm, (b) Fruit fly algorithm and (c) IPOPT algorithm

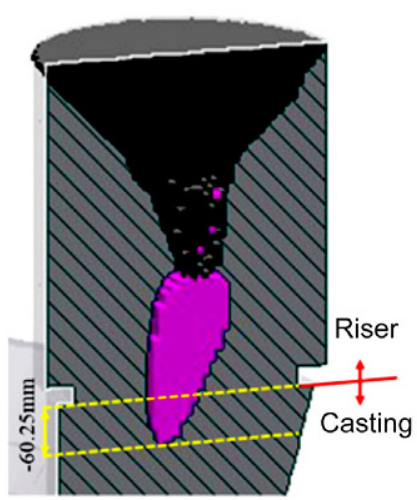

(a) Genetic algorithm

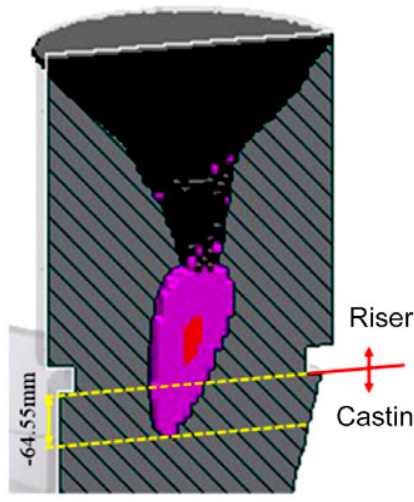

(b) Fruit fly algorithm

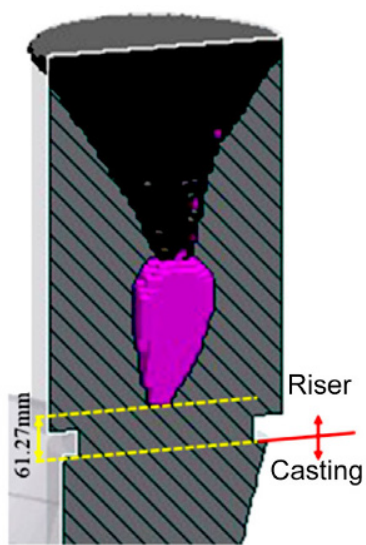

(c) IPOPT algorithm

Fig. 10: Shrinkage distribution in riser 
obtained the best results with the lowest amount of shrinkage porosities in the ad $\mathbf{s}$ tment ring while the $\mathrm{g}$ netic algr ithm and fruit fly algorithm showed similar optimization abilities. Furthermore, the IPOPT algorithm completed solidification faster than the other 2 algorithms did.

\section{References}

[1] Smart R F. Investment castings — the way forward. Metallurgia, 1988, 55(6): 288-288.

[2] Fursund V K. Das eindringen von stahl in forsand einflub der obserflachen reaktionen und der temperatur. Giesserei TechWiss, Beihefte, 1962, 14: 51-61.

[3] Annavarapu S, Apelian D, and Lawley A. Spray casting of steel strip: process analysis. Metalurgical Transactions A: Physical Metallurgy and Materials Science, 1990, 21A(12): 3231-3256.

[4] Flood S C, Hughes D T, Katgerman L, et al. Simulation of DC cooling during the casting of aluminium alloys. In: Proceedings of the 3rd UK National Conference incorporating 1st European Conference on Thermal Sciences, Institute of Chemical Engineers, Birmingham, England, 1992: 1213-1220.

[5] Liu B Shen H, Li W. Progress in numerical simulation of solidification process of shaped casting. Zidonghua Xuebao/ Acta Automatica Sinica, 1995, 21(3): 313-322. (In Chinese)

[6] Lewis R W, Manzari M T, Gethin D T. Thermal optimisation in the sand casting process. Eng Computation, 2001, 18(3-4): 392-416.

[7] Albu A F and Zubov V I. Optimal Control of the Solidification Process in Metal Casting. Comp Math Math Phys+, 2008: 48(5): 805-815.

[8] Tavakoli R and Davami P. Optimal riser design in sand casting process with evolutionary topology optimization. Struct Multidiscip O, 2009, 38(2): 205-214.

[9] Zhou J X, Shen X, Liao D M, et al. The research on the optimal solution for casting process design based on simulation software. In: Proceedings of the 71st World Foundry Congress: Advanced Sustainable Foundry. WFC 2014, World Foundry Organization, Bilbao, Spain, 2014.

[10] Gong X D, Liao D M, Chen T, et al. Optimization of steel casting feeding system based on BP neural network and genetic algorithm. China Foundry, 2016, 13(3): 182-190.

[11] Dantzig J A, lii C T, and Foster M. Modeling in Materials Processing. Applied Mechanics Reviews, 2002, 55(5): 60.

[12] Gunjal P R, Ranade V V, and Chaudhari R V. Dynamics of drop impact on solid surface: Experiments and VOF simulations, Aiche J, 2005, 51(1): 59-78.

[13] Zhou J, Liu X, Chen L, et al. Research on air quantitative prediction based on mold filling simulation of high pressure diecasting. In: Proceedings of the 6th International Conference on Physical and Numerical Simulation of Materials Processing. ICPNS 2010. Trans Tech Publications Ltd., Guilin, China, 2012: 1480-1486.

[14] Liu R, Chen L, Lin H, et al. Numerical Simulation of Steel Casting Coupling of Fluid Flow and Heat Transfer. Foundry, 1998, (6): 18-21. ( In Chinese)

[15] Gao S S and Yu Z Y. Calculate riser dimensions of steel castings using cubic equation mathematical analytic method. Foundry, 2000, 49(9): 533-537. (In Chinese)

[16] Holland J H. Adaptation in Natural and Artificial Systems: An Introductory Analysis with Applications to Biology, Control, and Artificial Intelligence. MIF Press, 1992.

[17] Pan W T. A new Fruit Fly Optimization Algorithm: Taking the financial distress model as an example. Knowl-Based Syst., 2012, 26: 69-74

[18] Dai H D, Zhao G R, Lu J H, et al. Comment and improvement on "A new Fruit Fly Optimization Alorithm: Taking the financial distress model as an example". Knowl-Based Syst., 2014, 59: 159-160.

[19] Watcher A and Biegler L T. On the implementation of an interior-point filter line-search algorithm for large scale nonlinear programming. Math Program, 2006, 106(1): 25-57.

The work was financially supported by the National Science and Technology Key Projects of Numerical Control (2012ZX04012-011), and the State Key Laboratory of Materials Processing and Die \& Mold Technology Research Project $(2014,2015)$. 